\title{
Studies of Externally Funded Research and Development Projects in Higher Education: Knowledge Sources and Transfers
}

\author{
Rauno Pirinen \\ Laurea University of Applied Sciences, Espoo, Finland \\ Email: rauno.pirinen@laurea.fi
}

Received 19 February 2015; accepted 8 March 2015; published 11 March 2015

Copyright (C) 2015 by author and Scientific Research Publishing Inc.

This work is licensed under the Creative Commons Attribution International License (CC BY). http://creativecommons.org/licenses/by/4.0/

(c) $\underset{\mathrm{EY}}{\mathrm{i}}$ Open Access

\section{Abstract}

This study is addressing the question: how can sources of knowledge be understood and realized in externally funded research and development (R\&D) projects. In this study, knowledge sources and transfers are concerned with identifying, creating, and disseminating of knowledge which is rooted in collaborative research settings and, in particular, in the context of learning from international research undertakings. Data were collected within the real R\&D projects accepted by the European Union and the Finnish Programmes for Research and Innovations. The study focused on six knowledge sources and knowledge transfers in the form of: 1) knowledge transition and sharing, such as shared or diffused knowledge; 2) knowledge transformation, such as knowledge from legacy service-systems or cultures; 3) inquired knowledge from domain or field, such as traditional acquisition related knowledge; 4) focused knowledge or led knowledge, such as regional R\&D agenda or research consortium connected knowledge which can be adopted for radical innovations; 5) knowledge co-creation and knowledge building, such as improving knowledge collectively upon experience, quality or action data; and 6) artifact and service related embedded-implicit knowledge, such as knowledge inside a service-system which can only be observed. The research findings of this study are in line with the literature and previous studies that argue that knowledge itself is an increasingly important source to competitive advantage, and a key to the success of modern organizations and creative higher education, strengthening the collective expertise, industry-service clusters, employees and competitiveness in global economy.

\section{Keywords}

Knowledge Economy, Knowledge Sources, Knowledge Transfers, Learning by R\&D 


\section{Introduction}

In this study, the integrative learning approach as Learning by R\&D was utilized to create an understanding of learning experiences and research processes in externally funded R\&D projects. The purpose was to improve collective learning methods and practices by utilizing knowledge gained from R\&D capabilities originating from integrative environments in which integrative learning spaces such as shared work packages are used in practices of international research consortiums. In a late industrial concentrated economy, the expected form of knowledge is tacit or codified. This kind of knowledge is based mainly on three perspectives: the information gathering metaphor, the participation metaphor and the knowledge creation metaphor. Here, the expanded approach is on emerging knowledge economy, in which, knowledge is referred to as: context-depended; path-depended; cultural-depended; space-depended; led or diffused; as well as, profiled, focused or co-created. In this case, the tacit dimension of knowledge is recognized, however in slight focus, yet the tacit is difficult to the assessment processes in mechanisms of higher education institutions. The study has been concluded between 2010 and 2014 at Laurea University of Applied Sciences in Espoo and in cooperation with international R\&D consortiums, the unit of analysis was as a form or type of knowledge, such as source of knowledge, transferred knowledge, focused knowledge, disseminated knowledge or shared knowledge in externally funded research projects.

The R\&D collaboration with higher education institution and many other regional-national-international competence and knowledge producers, such as firms, entrepreneurs, funding organizations and other academic institutions, has gained increasing importance in regional and national development and practical and scientific perspectives. The significant focus of higher education is in achieving a role as co-operator and trusted partner of higher education functions, R\&D networks and research consortiums, and combining useful knowledge from multiple sources and co-creating it with other participating actors for novel and benefiting competences and capabilities which are related to authentic R\&D projects, clusters, innovation systems, industry, research consortiums, and regional and national configurations. In the middle of this focus, there is collective learning; then, the setting of this study is towards R\&D and learning integration and collaboration activities with students, teachers and regional networked R\&D actors, as continuum of studies by author (Pirinen, 2011; Pirinen, 2014).

In operative environment of this study, higher education institutions are traditionally seen as contributors of new knowledge, services and technology. However, a new positioning of academic field is taking place with regard to cooperation in emergent value networks, co-created innovation, the contribution of pioneering innovations, and regional development affecting social and global development and economic impacts. In this view, new types of action, integration, trust and collaboration are required for the stimulation of creative innovation in services, technology, economy and society. In the context of this study, it was expected that research conducted by learning and usefulness of knowledge, as different forms of R\&D related learning, which are based on the demands for development of the employment market, can be used in the workplace to generate new competence and regional capability which means an ability to do something, e.g., the regional capabilities to increase productivity in a region and development by using a research-oriented approach and support for a learner's imagination, creativity and creativeness in integrative learning transactions in interactions and functions of higher education institution and regional configuration, governance policy and strategy (Pirinen, 2008).

Here, the term "integrative model" is designed to the student-centred integration of regional development, $\mathrm{R} \& \mathrm{D}$ and higher education functions. The focus of "integrative way" is on collaborative means acting and learning in an interoperable and co-creative manner with other learners which are encouraged to develop their own ideas and train in competences to become developers and researchers at a regional-national-international level. In integrative model, the learning transactions and increasingly R\&D consortium related knowledge transitions then enables learners to contribute to their collective understanding, real targets, regional capabilities as well as emergent innovations from own ideas and lead-led innovation issues, as well as along themes of international research consortiums agenda. This study furthers the previous studies by author and extends the viewpoints of knowledge sources and transfers in real-world externally funded R\&D integration (Pirinen, 2013).

In this way of "integrative learning", an individual learns alongside with a workplace, school and R\&D community, as well as near with a learning organization and focused learning in region or global scale. The expected advances of this integration can be associated through various formal and informal structures such as R\&D networks and actors, especially to the growing students and learners to become specialized in their areas of novel expertise where an applicable knowledge is produced and mobilized in the collective R\&D related learning processes. In this study, the realization concept is named as Learning by R\&D or Learning within R\&D which addresses to the collaborative learning within regional innovation systems and development of regional-global 
learning paths as well as regional capabilities and R\&D profiles within collaborative mechanisms, events, national policy setting, and regional-national research strategy and regional configuration (Asheim, 2012; Best, 1990; Clark, 2007; Etzkowitz \& Leydesdorff, 1998; Harmaakorpi, 2004; Teräs, 2008).

The "study of knowledge" is called epistemology in literature. However, no single agreed upon definition of the term "knowledge" exists; there are numerous theories to explain knowledge and its sources and paths. In this study, the rationality and motivation to the description of the realized knowledge paths and related knowledge sources are in usefulness of these themes and categories for the data collection, analysis and triangulation in studies of real-world R\&D cases, research consortiums, and externally funded R\&D, especially for implementation and design of thematic studies and for studies of regional configuration and its integration strategy as thematic curriculum. Here, the term "knowledge" is addressed for the meaning awareness or understanding of something, such as facts, information, descriptions, skills, methods and competence, understood as the sum of what is known. Then, the term "knowledge" is used here to know how things are and how the world and information and data for R\&D investigation appear in global scale R\&D practice. It is expected in this study, that knowledge can be learned by experience, experiment, training or education such as in ways of discovering and Learning by R\&D. It is anticipated also here, that action bridges knowledge, competence and skills, then, these relations can be described in a thematic curriculum and syllabus for higher education studies.

In the context of study, the term "knowledge" also refers to understanding the complexity of the operative environment in order to identify the influences behind various phenomena and "knowledge paths" which not only refers to governance of contents and applications but also joins the understanding of processes and practices by which information and its dissemination efforts are produced, then this view includes path-dependency of knowledge and the terms "collaboration" and "shared" address to the realization of the real-world (authentic) R\&D which is implemented particularly in a study units and learning in a student-centred and collective way within R\&D action and regional R\&D configuration settings: cf. thematic curriculum (Pirinen, 2009).

As reasoning of the study, the expected knowledge is vital for R\&D as followed: for development of artifacts and services; for progress of human activity systems; for enablement of new technologies; for designing, testing and improving solutions, methods, models, classifications, techniques and functionalities; for advancement to leadership and management functions and collaboration ways; for progress of security, safety and risk management and systems; and for development of algorithms, data structures and databases. Then, the main academic advances of study is in the R\&D of information systems related functionalities, such as co-creation of knowledge for progress of information systems research, outcomes, sharing, dissemination and impacts.

In this study the used term "integrative learning space", such as "research consortium", is consisting of internal, external, national and international networks and forms of funded R\&D consortia, which help participators, build their own communities of work and expertise and emergent value hetworks. Competent graduates on higher education would then have comprehensive expertise and capabilities in various disciplines. This implies gathering and processing information, reflecting on one's own experiences, sharing knowledge with others and 'continuously developing one's own working methods, such as learner's sustainable and lifelong growing and development. These integrative learning spaces can take in account the thematic targets of regional configuration, regional strategies and needs of workplace development and knowledge co-creation.

Students of higher education are then in the center of the regional-global learning process, which conducts regional profiles, capabilities and configuration by bridging novel knowledge and competences in community of practice. In this study, the term "learner" refers to a student, teacher, researcher or participator who enriches their own competence through collaborative R\&D, by sharing expertise and learning from others, where R\&D collaboration for learning are used, and the "student" is used to address that a person is registered as a student in the data base of the Ministry of Education and Culture. Then, as significant academic contribution of this study is to address to the form of higher education models and theories which focuses into demands of the employment market and its development, teachers and employer representatives needed work together closely in an interoperative way as collective learning community (knowledge creating community) which can involve students and implementation of study units in higher education and share regional-national level R\&D, such as activities of international research consortiums and work packages as in the "integrative model" whole (Pirinen, 2013).

\section{Literature Review}

The foundation for the "knowledge economy" was introduced in the book The Effective Executive (Drucker, 
1969). Drucker describes the difference between the manual worker and the knowledge worker. The manual worker, according to him, works with his hands and produces goods, artifacts or services. In contrast, a knowledge worker works with his or her head not hands, and produces ideas, knowledge, and information. In this setting, Piore and Sabel (1984) explain how new and flexible production technologies are transforming and transferring. Best (1990) and Porter (1990) explain how such production networks, which are resilient and dynamic, take the form of regional or territorial production systems (Asheim, 2012; Best, 1990; Rutten \& Boekema, 2012; Storper, 1997). The term "knowledge economy" and its implications for the organization of production and services are currently accepted as emerging economic mainstream, in this review, mainly through (Best, 1990; Cooke \& Morgan, 1998; Piore \& Sabel, 1984; Porter, 1990).

In an industrial concentrated economy, inventions and innovations are concentrated in manufacturing and a limited number of service industries (Rutten \& Boekema, 2012). Here, value creation comes in the form of new production technologies and flexible production (Best, 1990). In a knowledge economy, the most central value creator is knowledge itself (Asheim, 2012; Malecki, 2012). In our view of globalization, students are going global by networked media and utilize internship-based knowledge relations, and businesses, regions, and countries are pipelined and networked by global knowledge and activities. The evolution theory of economic change, addressed on (Nelson \& Winter, 1982), has response in the context of this study. The focus is on the path-dependency nature of knowledge and competence development. The assumption of study is that the learning takes place in an innovation and scoped-thematic process, which is rooted in a genuine economic structure and its regional configuration, which includes strong elements of path-dependency, cultural-dependency and thematic nature. Here, as key term of this study, the assumption of term "path" and its dependent nature can be in resonance with: "what we can do in our own way is related to where we are and then where we have been", as notedin (Johansson \& Ylinenpää, 2012; Nelson \& Winter, 1982; Rickne, Laestadius, \& Etzkowitz, 2012).

The academic foundation of higher education itself has long traditions. For example, a strong resonance of this R\&D related study of knowledge paths can be found far behind the Democracy and Education (Dewey, 1916: p. 33), "education is not an affair of telling and being told, but an active and constructive process". Then, Dewey continues: "Its enactment into practice requires that the school environment be equipped with agencies for doing, with tools and physical materials, to an extent rarely pattained. It requires that methods of instruction and badministration be modified to allow band to secure direct and continuous occupations with things. Not that the use of language as an educational resource should lessen; but that its use should be more vital land fruitful by having its normal connection with shared activities."

Dewey presented that the teacher should participate within that learning process: the teacher role should not be one to stand at the front of the room doling out bits of information to be absorbed by passive students. Instead, the teacher's role should be that of facilitator and guide. Thus, the teacher becomes a "partner in the learning process, guiding students to independently discover meaning within the subject area” (Dewey, 1897: p. 231). Dewey's definition of inquiry: "Inquiry is the controlled or directed transformation of an indeterminate situation into one that is so determinate in its constituent distinctions and relations bas to convert the elements of the original situation into a unified whole” (Dewey, 1938: p. 104).

Dewey explained learning from a perspective of learning by passive absorption to learning by doing, here it can be understood that this "doing" is "R\&D related", and learning by direct contact with things as well as learning through real-life contexts and inquiry." Dewey's classical educational theories and models have large scale aspects to the views of learning, and almost none of current learning approaches are supposed to be totally new, rather continuums by John Dewey, e.g., (Bereiter, 2007; Brown, Collins, \& Duguid, 1989; Engeström, 1987; Gibbons et al., 2008; Kolb, 1984; Mezirow, 1981; Scardamalia \& Bereiter, 2006; Sfard, 1998; Vygotsky, 1978).

Revans (1982) describes the term "action learning” which particularly obliges subjects to become aware of their own value systems, by demanding that the real problems tackled carry some risk of personal failure, so that "the subjects can truly help each other to evaluate in what they may genuinely believe" (Revans, 1982), in (p. 627). In earlier context of this study, the action learning processes within action research frameworks were used as learning processes for development of the capabilities and professional competences of individuals, teams, overall organizations and emergent network (Lewin, 1946). In Pirinen (2009), the term "Learning by Action Research" was understood as action learning process whereby the learner studies their own actions and experience in order to improve professional competence, capability and performance (Lewin, 1942; Mezirow, 1981; Revans, 1982). Here, learners acquire knowledge through action and practice with co-instructions, learning 
space, living lab, test bed, workplace, and communities of work.

Sfard (1998) elicited two metaphors of learning to guide the work of students, teachers, and researchers as learners: the acquisition metaphor and the participation metaphor. According to Sfard (1994), the meaning of abstract concepts is created through the construction of appropriate metaphors. Sfard holds that metaphors, or figurative projections, from the tangible or real world onto the world or universe of ideas are the basis of understanding. Sfard suggests that the role of the metaphor of an object in the learning and teaching processes cannot be loverestimated. Sfard (1998) says that different metaphors may lead to different ways of thinking, land there is no clear border between metaphor and theory."

According to Sfard (1998: p. 5), the acquisition metaphor of learning is old: "Since the dawn of civilization, human learning has been conceived of as an acquisition of something." This statement addresses the act of gaining knowledge and the growth of knowledge in the process of learning, which often has been analyzed in terms of concept development. Concepts are to be understood as basic units of knowledge that can be accumulated, refined and combined to form richer cognitive structures (Lewin, 1942; Peirce, 1878). The learner is seen as a person who constructs meaning and knowledge. Sfard (1998: p. 5) describes: "the language of knowledge acquisition and concept development makes us think about the human mind as a container to be filled with certain materials and about the learner as becoming an owner of this material." The acquisition metaphor, in terms of action, is seen as "transformation, reception, acquisition, construction, attainment, development, accumulation and grasp and the teacher should help the student to attain the appropriate goal by e.g. delivering, facilitating and conveying” (Sfard, 1998: p. 5). In this study, the acquisition metaphor represents a traditional view of learning in which an individual acquires abstract and generalizable knowledge by following pre-given and clear-cut rules or algorithms (Engeström, 1987; Schaefer, 1967; Sfard, 1998).

The focus of the participation metaphor is on cultural, communal, and situated aspects in learning, where activities and practices are the focus of learning (Sfard, 1998). In the context of study, the participation metaphor emphases on cultural, communal, and situated aspects of learning, where activities and practices are an important part of learning. Sfard (1998) notes, that the decision to view learning as integration with community in action gave frise to quite a number of conceptual frameworks. In this sense, it would be noteworthy that the theory of situated learning and the theory of distributed cognition have similarities with Sfard's participation metaphor: In the integrative learning space of this study, "cognition" is understood as a mental process of knowing, including aspects such as awareness, perception, reasoning, and judgment and then "cognitive complexity" refers to the numbers of non-automated cognitive operations or strategies that learners must implement to a specific learning goal (Bredo, 1994; Brown et al., 1989; Lave, 1988).

The participation metaphor of learning should be viewed as a person interested in a certain kind of activity rather than in accumulating private property or possessions. Here, learning is conceived of as a process of becoming a member of a community, communicating in the language of that community, and acting according to its norms. The norms themselves are to be negotiated in the process of consolidating the community. While the learners are newcomers and reformers of practice, the teachers are preservers of the community. From the lone entrepreneur, the learners are an integral part of a group. Participation is almost synonymous with "taking part" and "being a part", and "both of these expressions signify that learning should be viewed as a process of becoming a part of a greater whole” (Sfard, 1998: p. 6). In the context of study, this perspective is involved with participation to the research consortiums, regional R\&D configuration, policy functions, and strategies in higher education institution (Pirinen, 2013).

In this study, the term "knowledge-creation" has similarities and roots in the creative views of constructivism and on the critical realist and pragmatic background of inquiry and learning, which relies on interaction between individuals, communal processes, events and mechanisms. Here, knowledge-creation joins learning by R\&D, workplaces and consortiums (Argyris \& Schön, 1996; Nonaka \& Takeuchi, 1995; Tuomi, 1999). These references have all focused on the creation fof fconceptual and cultural knowledge within processes of communities of expertise. They all agree that events, artifacts and increasingly service-systems are part of a community's collective knowledge, and artifacts have an effect on learning, where the focus is on building knowledge. In this study, the knowledge-creation addresses a collaborative effort to enhance some subject matter, i.e., learning scope or integrative components in learning, and it relies on an interaction between individual and communal process. West (2009) describes a view of knowledge-creation which addresses the processes of transformation of knowledge and relates corresponding social co-creativity in practices: here, knowledge-creation in R\&D related learning can be understood in way that learning is seen as analogous to inquiry, e.g., Dewey's processes of 
inquiry, especially to processes of investigation where something new, such as service, method or artifact, is created and the initial knowledge is either substantially enriched or significantly transformed during the process. In this study, the knowledge-creation or as its extended form knowledge co-creation approach of R\&D related learning is expected to provide a way of integration of lines between problem-based, solution-based, acquisition-based, and participation-based thinking (Barrows \& Tamblyn, 1980; Burr, 1995; Eraut, 1994). In this study, this relative new term "co-creativity" is used regarding collaboration, which is seen as the "secret to breakthrough creativity" (Sawyer, 2008) and which would lead to a group's advancements in creativity in co-creation processes of services, artifacts and methodology, and knowledge is placed in collaboration with innovation systems and integrative functions of regional development and higher education (Gibbons et al., 2008; Pirinen, 2008; Ståhlbröst, 2008; Teräs, 2008). According to West (2009), the collaboration during the creative process may not be new, but the necessity of group creativity and co-creativity is: "with the information explosion and growing necessity of specialization, the development of innovations will increasingly require group interaction at some stage of the process" (West, 2009).

The distinction between basic and applied sciences, as described in (Simon, 1996), is commonly taken as one of the grand lines that divide and serve to classify types of inquiry. Here, the distinction of science as dual model of research plays role in science policy and governance of Finnish higher education system. Although this distinction is hard to define, our policy, governance and academia funding functions seems to be lost without the dual model, it is simply needed and concluded to the "Table 1 ".

\section{Table 1. Distinction of science as dual model of research in viewpoints of this study.}

\section{Basic science}

Knowledge source and transfer:

Purpose of data collection:

Unit of analysis:

Methodology:

Evidence:

Dependency:

Knowledge source
and transfer:

Purpose of data collection:

Unit of analysis:

Methodology:

Evidence:

Dependency:
Basic research which is also called pure research or fundamental research is a systematic study directed toward improved understanding or knowledge of the appropriate aspects of phenomena without specific applications or products or services in mind. Here, research for understanding and descripting.

Developing new knowledge as natural system by applying scientific laws; collaboration between research units and work packages in research consortiums; includes clear plans for vital knowledge creation; lays to the foundation for advancements in knowledge that lead to applied gains later on.

Quantitative or qualitative units of analysis which rarely contributes to the R\&D concerns.

Explanatory research; case study; multiple case study; cross-case analysis; exploratory study; and descriptive study.

Understanding; description; model; concept; new ideas and principles towards theories; middle-range theories; and the foundations of R\&D in different fields.

Objective and researcher as outsider; and outsiders research substance experts.

\section{Applied science}

Applied science as research is approached as a form of systematic inquiry involving the practical application of science, here, such as services and artifacts. It accesses and uses some part of the body of knowledge in research community, e.g., referred theories, knowledge, methods, and techniques, for dedicated purposes and for applying and combining existing knowledge in new way. Here, research for development and utilizing.

Knowledge synthetic; knowledge for building; improving; testing; production data; improving action; and engineering based knowledge.

Project; information system; service; experience; event; method; structure; and mechanism.

Inductive or deductive research; design science research in information system which focuses to the thinking, building, improving and evaluating services and artifacts; information systems research; last-mile research; and action research; emergent applications and services.

Sample of evidence: know-how related samples; information systems; hardware and systems engineering.

Research as more insider or outsiders with insiders; frequently, the roles of participators and researchers are descripted explicitly in documents of study. 


\section{Methodology}

The data collection of this study was cumulative, and it was systematically used for a qualitative analysis between January, 2010 and March 2014. The data was collected according to externally funded R\&D projects ( $\mathrm{n}=$ 10 ) at Laurea UAS which were analysed as cross-cases and which included followed sub-categories: management data, $(n=89)$ files, which includes strategies, drafts of visions, legislation, papers of regional focus, scoreboards and indicators; data of development days and reviews, $(n=92)$ files, which includes data displays, evaluations, reviews, learning diaries, development proposals and reports; data of FINHEEC evaluations regarding the regional development and $R \& D,(n=4)$ evaluation reports; and feedback data from students, $(n=87)$ reports from the INKA system as feedback data and themed interviews of learners during different phases and areas of studies.

This study concludes the realization of R\&D and regional development functions of higher education institutions in response to the progress of information systems, security management, and service programs at Laurea UAS. This study addresses to the integrated and student-centred R\&D projects, which were advances by R\&D consortiums and agenda within master's, bachelor's and degree education in the programs of information systems $(n=528$ students in 2012), security pimanagement $(n=403)$, and services $(n=676)$. Altogether there were about 7500 students in every year at Laurea, between in 2010 and 2014.

In this study, the multiple-case study approach was used; the method is well known and explained fine in references (Benbasat, Goldstein, \& Mead, 1987; Dubé \& Paré, 2003; Eisenhardt, 1989; George \& Bennett, 2005; Gerring, 2007; Miles \& Huberman, 1994; Patton, 1990; Robson, 2002; Stake, 1995; Yin, 2009). Here, multiple case study follow replication logic and selected cases serve in a manner similar to multiple experiments, with similar results, a literal replication or contrasting results in a theoretical replication predicted explicitly at the outset of the investigation.' In this study, the case study analysis is bringing an understanding of a complex issue and object and can extend experience or add strength to what is already known through previous research and literature. Here, case studies emphasise a detailed contextual analysis of a limited number of events or conditions and their relationships, when the relevant behaviour is not manipulated and the role of research is "objective outsider" (Herr \& Anderson, 2005).

Reference (Yin, 2009) notes that the simplest multiple-case design would be the selection of two or more cases that are believed to be literal replications, more complicated multiple-case design would return result from number and types of theoretical replications, such as middle-range theories (George \& Bennett, 2005). In this, the end of data collection and analysis was indicated in by saturation, when no new information was emerged for research purpose (Campbell \& Fiske, 1959; Corbin \& Strauss, 2008). In this study, data of externally funded R\&D projects $(n=10)$, which included views to the sub-categories was analysed, followed:

RIESCA: Rescuing of Intelligence and Electronic Security Core Applications (RIESCA) was the first of our externally funded R\&D projects, running between October 2007 and March 2010. The research of RIESCA addressed a number of systems, such as transport and logistics, power and telecommunication, and hydropower0and nuclear power stations, which are critical to the day-to-day functioning of any technologically advanced society such as Finland. In RIESCA, the understanding and design of the R\&D consortiums as a steering driver and relationships of trust-based networked expertise were found. This project was implemented in study units in an interoperative and student-centered manner. It represents the beginning of student-centered R\&D discursion in publications of the Laurea UAS (Pirinen \& Rajamäki, 2010).

SATERISK: Satellite Positioning Risks (SATERISK) was initiated by two security imanagement students at Laurea UAS. It evolved into a substantial three-year R\&D project"between 2008 and 2011 which was collaboratively shared with universities, an industry, and a service partner, SATERISK was funded by the Finnish Funding Agency for Technology and Innovations (TEKES). The funding of SATERISK was secured on November 14, 2008 and allocated for September 1, 2008 to August 31, 2011. The case of SATERISK proved that, in itself, student expertise and a student-workplace relationship could be seen as a knowledge transfer bridge, a trigger, and a driver of externally funded R\&D projects. Regarding this study, SATERISK has derived (FP7) spin-off, PERSEUS. Here, the focus of SATERISK is on a discovery of a path-dependency nature and a knowledge economy in the evolution of research consortiums (Rajamäki, Pirinen, \& Knuuttila, 2012).

ORE: The Open Rendering Environment case ran from June 2008 to December 2009. Rendering is the process of generating 3D images and movies on computers. The ORE project aimed to bring the Berkeley Open Infrastructure for Network Computing-based Big and Ugly Rendering Project distributed rendering service to Finland. This goal was realized by the opening of the "Renderfarm" service in June 2009. The Renderfarm service 
is the world's first publicly distributed rendering service advocating the use of "creative commons licenses." The ORE project also aims to help companies and universities adopt the Blender open-source 3D-modeling suite in their everyday workflow. While creating new information about social behavior and distributed computing, Laurea and the project also functioned as a pilot project for TEKES, as it studied the possibility of using a Finnish UAS as a supporting structure for bringing new technologies into the reach of small and medium-sized enterprises. ORE was the pure creation of a student, and it resulted in the establishment of a spin-off company.

CoCo: From Co-production to Co-creation (CoCo) was the most student-related research project, running between September 2010 and December 2012. Altogether, over 200 students worked together and completed the following project tasks: 120 business students were responsible for forming the project contracts at the beginning; 50 information systems students developed the Virtual Co-creation platform, and two information system interns worked as supervisors of these information systems students; 30 business students built the first draft of the analysis tool developed in the project; one business student worked as a project assistant taking care of the administration and organizing the events; and three master's degree service students service analysed the current state of the case companies' business approach as part of their master's theses. In addition, a tool for analysing a company's co-creation approach was developed. In this research, students were at the center of development in new roles by customers and its role change in practice. In this view, consumers and individuals take a more active role in various paths of value creation, and the focus of the value-creation processes is rapidly shifting from a supplier-company-centered view to a more customer-centered approach that aims to support customer experiences and joint value co-creation.

MOBI: The Mobile Object Bus Interaction (MOBI) ran from September 2010 to October 2013. The target of MOBI, as a Finnish national research, development, and innovation program, was to create a common information and communication technology (ICT) hardware and software infrastructure for all emergency vehicles. This infrastructure includes devices for voice and data communications, computers, screens, printers, antennas, and cabling. Additionally, interlinking with factory-equipped vehicles’ ICT systems was studied. The project utilized the results of a related research project and aimed to develop product concepts that have potential in both domestic and export markets (Tikanmäki, Rajamäki, \& Pirinen, 2014). The R\&D scopes of MOBI have been integrated into the realization of study units since 2010. MOBI is a spin-off of RIESCA as continuum.

MACICO: Multi-Agency Cooperation In Cross-border Operations was addressed to the interactions and research and development (R\&D) of security organizations and cross-border processes. The shared MACICO processes, described in this study, operates usually in dedicated networks and using of own systems and services, but which in some critical missions could directly and indirectly benefit by respective sharing of external activities, distribution of mission critical information, and sharing of information systems or information intensive infrastructure. In a short-term scenario, MACICO project was addressed to the needs for improved systems, tools and equipment for radio communication in cross-border operations and during operations which were taking place on the territory of other member states as critical over border situations. In a long-term perspective, MACICO encompassed the interoperability issues of European countries and for formulation of transition from currently deployed legacy networks into the future broad band networks. The timeframe of MACICO was between December 2011 and December 2014.

PERSEUS: Protection of European Borders and Seas through the Intelligent Use of Surveillance (PERSEUS) is coordinated by INDRA Sistemas with $n=29$ partners. The timeframe of the PERSEUS research was between January 2011 and December 2014. In this study, the selection of PERSEUS as a case represents a program and research consortium that aims at the large-scale integration, validation, and demonstration of novel systems and symbolizes European research collaboration, providing a federative frame to join research and steering in areas of significant European interest. The focus of the PERSEUS investigation is consortium functions and research on international knowledge transition and path-dependency mechanisms (Pirinen, Sivlén, \& Mantere, 2014).

AIRBEAM: AIRBorne information for Emergency situation Awareness and Monitoring (March, 2011 to February, 2015) is a Seventh Framework Programme (FP7) project related to crisis management. The goal is to develop a multi-platform approach to situational awareness for crisis management, especially utilizing Unmanned Aerial Vehicles (UAVs), aerostatic platforms and satellites. In addition to EADS, the AIRBEAM Consortium includes 22 partners, including some of the largest high-tech companies in Europe. The role of Laurea is as the coordinator of Work Package 1 of AIRBEAM, which focuses on studying potential concepts of use and specifying end-user requirements. This work is in close collaboration with end-user organizations as continuum of our own budget funded May Fly pilot between January, 2009 and December, 2010. 
ABC4EU: Automated Border Control Gates for Europe is European Union wide R\&D project and involves a Consortium of 15 partners from 8 different countries. The purpose is to make border control more flexible by enhancing the workflow and harmonizing the functionalities of automated border control gates. Project started in January 2014 and will last for 42 months. The project is led by INDRA Sistemas S.A. from Spain. During the last years, many ABC Gates have been deployed in the main European airports, most of them as pilot projects intended to test their capability to improve the border crossing processes in aspects such as speed, security, automation, and false rejection reduction. In particular, harmonization would be required in areas as e-passports management, biometrics, gate design, human interface, parallel processes, signalling and interoperability.

EU_CISE 2020: European Union's Information Sharing Environment addresses to steps forward along the accomplishment of the European roadmap for Common Information Sharing and Distributed Systems and Services Environment. This current project attains the widest possible experimental environment of innovative and collaborative services and processes between European maritime institutions and takes as reference a broad spectrum of factors in the field of European Integrated Maritime Surveillance, arising from the European legal framework, as well as from earlier studies, pilot and related R\&D projects. The timeframe of EU_CISE 2020 is between 01/06/2014 and 01/06/2017.

In this study, the research design included that the "internal validity" can be addressed to the establishment of casual relationships; the targets of the studies focused on increasing the trustworthiness and understanding that studies make sense and are credible enough for research consortiums audiences and information systems development. The design of this study was based on a combination of a thorough understanding of the theoretical framework, and wide experimental knowledge, e.g., the concepts and their relationships, which were used to explain functional frames and its meaning concerning the research questions. In turn, the term "reliability" refers here to demonstrating that the operations of a study, such as the data collection procedures, can be repeated with the same results. Due to the environment and management of the research organization, the performed interventions and spirit of action might be difficult to irepeat. However, the sustain data collection of R\&D projects, large number of investigated cases and related themed data categories to analysis can be reflected in verification of reliability. See audit of case study analysis in (Dubé \& Paré, 2003; Miles \& Huberman, 1994; Robson, 2002).

\section{Research Findings}

The research question of this study was: how paths and sources of knowledge can be understood and described in externally funded research and development projects. In addressing this question, the literature review was included for the understanding of relations between the key terms, such as knowledge, learning and knowledge economy in the context of study. The research data collection for this study was cumulative, and it was systematically used for a qualitative analysis between January, 2010 and March, 2014. The study addressed to the integrated R\&D projects and related research consortiums, which were realized by R\&D collaboration and implemented with connection of study units within master's, bachelor's and degree eeducation in the programs of information "systems, security management, and services at Laurea UAS. The criterion of founded knowledge paths and sources was that an achieved form of knowledge can be assessed in studies of higher education institution.

The overall research finding of this study can be outlined that building of useful knowledge and innovation processes has become increasingly complex, multidisciplinary, trust-based, co-created, path-depended, and globalized. Some examples: 1) the path-dependency in case SATERISK which has derived spin-off the PERSEUS and which has been initialized in the case RIESCA; 2) the trust-based networked expertise relationships and multidisciplinary approach were founded in the RIESCA; 3) the CoCo research projects focused on knowledge building in the service field by encouraging the development of competitive value co-creation service concepts and usefulness of knowledge also in multimethodological manner; and 4) the case PERSEUS, ABC4EU and EU_CISE represents a multidisciplinary research programme and shared research consortium which was targeted at large-scale integration, validation and demonstration of novel systems and it symbolizes European research collaboration, providing a common learning space to join research and steering in areas of significant European interest.

The data of investigated four cases connected a large variety of knowledge related paths and knowledge interconnections for innovative startups and work places, and there were direct implications such as, students and companies which both were increasingly going to be global oriented. The "path of knowledge" and its path-depended nature can be comprised here as: "what we can do in our own way is related to where we are and then 
where we have been, in this flow of knowledge, one key is in the usefulness of knowledge and knowledge paths in action and in understanding of path-dependency and cultural-dependency of achieved knowledge for development and research purposes, mutual confidence, governance, common sharing, and dissemination.”

According to data of this study, the paths of knowledge and related sources of knowledge can be described followed: 1) knowledge dissemination and transition, e.g., knowledge from international class research areas which can be further progressed, modularized and utilized, in this study, the international knowledge transitions effected into the research and work designs and understanding of appropriate research gaps, e.g., related study units, integrated word packages and metrics in PERSEUS, MOBI and MACICO; 2) knowledge transformation, e.g., transformations from knowledge of legacy systems and transformation of knowledge which is related to the path-dependency, context-dependency, organization-dependency and cultural-dependency, in this study, the knowledge transformations were enabled in the design research studies in information systems and action research studies in CoCo, RIESCA, ABC4EU and EU_CISE; 3) inquired knowledge, as to migrate the elements of the original situation into a unified whole, e.g., knowledge which is related into experience, event and mechanism in the field, the path of inquired knowledge can include systematic research as knowledge inquiring for validation of service, systems or standards, the inquired knowledge often included deductive and analytic investigations as well as collaboration between networked research units, and type of inquired outcomes can be described as "universal”, e.g., case studies in PERSEUS, MOBI and MACICO; 4) focused knowledge or thematic knowledge e.g., led knowledge which is related to the regional-national research agenda; aims of research consortiums; it can produces economic value in knowledge transition, utilization and dissemination; focused knowledge is combining existing knowledge in new way for furthering of focused theme; it is rather inductive; e.g., interactions with customers and suppliers; focused knowledge is often context-depended and thematic; in context of this study, the focused knowledge was achieved by case studies and how and why questions in CoCo and design research studies of SATERISK and AIRBEAM; 5) co-created knowledge or knowledge creation paths such as building of knowledge which is related to new artifact, service or expanded ontology in such forms as meanings, signs and symbols, the focus is in creation or co-creation process, and outcomes includes culturaldependency and work place dependency, in context of this study, the knowledge creations were achieved by service design, information systems design research and multimethodological studies in CoCo, ORE and SATRISK; and 6) embedded-implicit knowledge within service-artifacts such as service related ontology or knowledge of applied process, in this study, the achievements of service-artifact related knowledge was such as benchmarking and cross evaluations tools in CoCo and PERSEUS. The most appropriate examples of paths and sources of knowledge are concluded to the followed Table 2.

Table 2. Transfers and sources of knowledge in externally funded research and development projects.

\begin{tabular}{|c|c|}
\hline \multicolumn{2}{|r|}{ Disseminated knowledge (knowledge from research and development) } \\
\hline $\begin{array}{l}\text { Knowledge } \\
\text { source and } \\
\text { transfer: }\end{array}$ & $\begin{array}{l}\text { Knowledge transition and dissemination from international level R\&D results; reconceptualization of latest useful } \\
\text { knowledge; socialization of new knowledge; dissemination of emergent knowledge; development of scopes and } \\
\text { themes for future studies; knowledge is created by expertise; studies and training in work place; workshops; and } \\
\text { reviews. }\end{array}$ \\
\hline $\begin{array}{l}\text { Purpose of data } \\
\text { collection: }\end{array}$ & $\begin{array}{l}\text { Dissemination of meaningful and useful knowledge; knowledge for incremental or radical inventions and } \\
\text { innovations; cognitive and practical progress; improvements of expertise competence; facilitation of R\&D related } \\
\text { learning; progress and creation of school and academy; exploitation of knowledge reserves and mobilization; } \\
\text { advances by new knowledge for future development; and regional-global capabilities, policies and intellectual } \\
\text { capital. }\end{array}$ \\
\hline Unit of analysis: & $\begin{array}{l}\text { Presentation; proposal; technology; protocol; system; computer-information language; unit of standard; measure; } \\
\text { dissemination channel; study unit; R\&D group; R\&D networks; policy; cluster; cultural proximity; direct impact; } \\
\text { indirect impact; and relations between communities. }\end{array}$ \\
\hline Methodology: & $\begin{array}{l}\text { Case study; grounded approach; research for improving or building disseminated service or artifact; network } \\
\text { analysis; discourse analysis; design science research; information systems research; last-mile research and action } \\
\text { research. }\end{array}$ \\
\hline Evidence: & Direct impact; indirect impact; action related changes; and cultural changes. \\
\hline Dependency: & $\begin{array}{l}\text { Disciplinary-dependency; policy-dependency; expertise-dependency; common knowledge sharing and dissemination } \\
\text { way or channel dependency. }\end{array}$ \\
\hline
\end{tabular}




\title{
Continued
}

Transformed knowledge (knowledge from legacy systems and cultural dependency)

\begin{abstract}
Knowledge source and transfer:

Knowledge transformation from legacy systems; knowledge transformation across different cultures for communication and information systems development; e.g. process of enterprise knowledge extraction from relational database and source code of legacy information systems; e.g. analysis of data reverse engineering and program techniques for the schema and semantics of information systems building; and for interaction across cultural boundaries.
\end{abstract}

Purpose of data Building and improving processes; updating legacy systems to new or improved products and services; renovating collection: legacy processes; and service design.

Unit of analysis: System; routine; process; service; cultural proximity; domain and ontology.

Information system research; design science research; service design studies; action research; research of Methodology: knowledge extraction; research of relational database, data reverse engineering, and analysis of legacy information systems.

Evidence:

Ontological contribution; constructs; models and cross-border methods; and common information and systems sharing across borders.

Dependency: Strong development path-dependency and cultural-dependency.

Inquired knowledge (knowledge from experience, events and mechanism)

Knowledge source and transfer:

Purpose of data collection:

Unit of analysis:

Methodology:

Evidence:

Dependency:
Acquisitions related to phenomenon or experience which maters and are meaningful; knowledge related to events and mechanisms; significance of target in regional-global scale; a systematic study directed toward improved understanding or knowledge of the fitting aspects of remarkable phenomena without specific applications or products or services in direct mind.

Adopting subject related knowledge; structures and schemas; focus in knowledge which is useful and maters in context; ontological or epistemological implications; improved understanding for development of artifacts, resources and work places.

Individual; student; participator; actor; group; work place; organization; and region.

Deductive and analytic investigations; studies of problem solving; studies of research scopes; testing and validation studies; studies of experience or cognitive processes; case studies; progressive inquiry for service or artifact development; critical realist studies; interviews of experts; questionnaires; observations; document analysis; and multiple methods.

Experience; structure; model; display; classification; and description.

Context-dependency; path-dependency; and cultural-dependency.
Knowledge source and transfer:

Purpose of data collection:

Unit of analysis:

Methodology:

Evidence:

Dependency:
New and emergent knowledge sources as lead knowledge sources, open sources and open innovations which are especially addressed for value-addition purposes; in the environment of this study, the expected advance is that participators can use external ideas as well as internal ideas, and internal and external paths, as well as research consortium paths and knowledge as one way into national-global markets; the focused knowledge path address to the value-fadded chains which includes great economic potential and options to furthering of economical collaboration by sharing risk and sharing possible reward.

Radical innovations; proliferation; focused education; regional-national configurations; specialization; knowledge-based competition; building and improving business and service strategy or model; conferences; seminars; workshops and meetings for competitiveness.

Idea; scope; target; product; service; value-added chain; economic potential; open source; and interest group.

Case study research, design science research; last-mile research and action research.

Effect on economic growth and employment; inventions; samples towards on value-added ichains with high economic potential; creation of new jobs and strengthening of innovative potential; samples of enhancing strengths; successful new markets; samples toward social demands; samples of hetworking and clustering; completed shared $\mathrm{R} \& \mathrm{D}$ projects and infrastructure; and shared risk assessment.

Strategy-dependency; expertise related; concept-dependency; target-dependency; and community-dependency. 


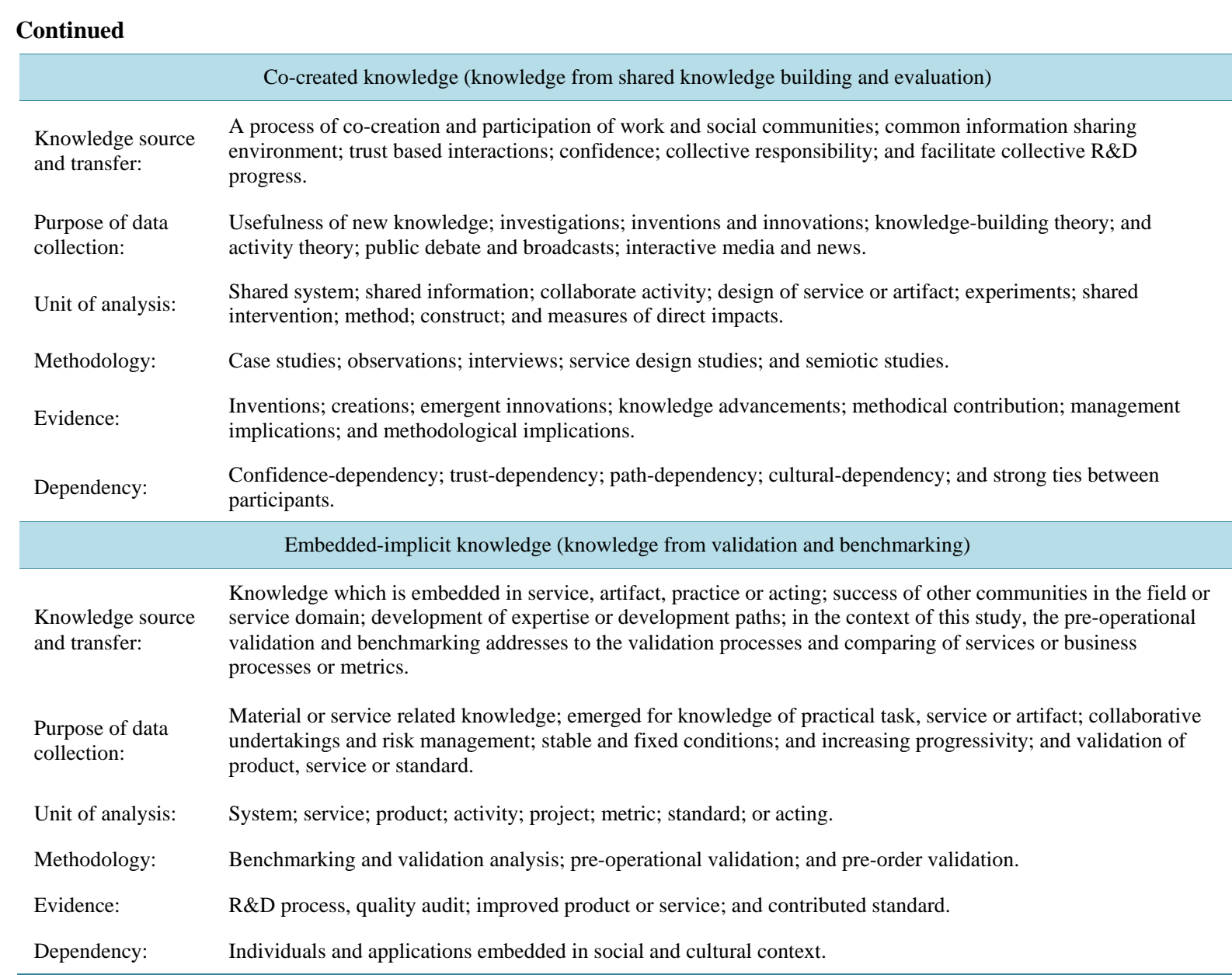

Along with R\&D projects as cases in this study, a knowledge transferred from described sources in Table 2, were then assimilated in the Learning by R\&D, which was intended to an integrative way of learning as approach of studies where individuals learns along with a workplace, school and R\&D community, such as research consortium, as well as, alongside with a learning organization and across of borders and silos as in learning space which can be individual-global oriented. Then, Learning by R\&D can be associated through various formal and informal structures such as R\&D networks and actors, especially to a growing students and learners to become specialized in their areas of novel expertise where an applicable knowledge and its sources were produced and mobilized in the collective R\&D related learning processes. Then, Learning by R\&D or Learning within $\mathrm{R} \& \mathrm{D}$ addresses to the collaboration within regional-national innovation systems and development of regional focused and strategic learning targets as well as regional capabilities and R\&D profiles within confidence and governance policy in mind. In this learning space, Learning by R\&D within student-centred R\&D were based on and included R\&D and consortium collaboration, the student-centred R\&D comprised a student's mind-fon and hands-on activities, social interaction, creating something new in learning within R\&D, and knowledge sharing and collaboration between individuals and communities of work land communities of R\&D.

\section{Discussion}

The discussion of two imperative terms SCOPE and PROBLEM in R\&D related learning can be furthered followed as ontological implications: in this study, the term "scope" was expected to be useful for resiliency as elastic nature and for focusing to student's viewpoints, learning paths, creativity and knowledge processes related into students own work, as for understanding knowledge sources and paths in world of work. This setting of study was realized as integrative learning space in where: 1)" the term "scope" was realized to be useful to a satisfaction, atmosphere, mutual trust, confidence land "learning to like or dislike" in a learning space where 
student takes “a \&scope” and makes his own personal activity, "creation, improving and validation into the selected or shared learning target as scope, e.g., as SATERISK which was a result of scope-based thinking, learning was in line with a schema of learners; 2) a "scope" was not loaded by teacher's knowledge in beginning, then, a scope related knowledge can be achieved openly by student's viewpoints and interests, not teacher's or problembased viewpoints as emancipatory approach to learning; 3 ) here, the term "learning scope" address to a mental or resilient physical target |ror subject matter that something deals with in networking and lifecycle of learning; 4) the aim of using the "elastic scopes" in beginning was to support a student's imagination and creativity in learning, and the assumption was that the "elastic scope" generates band maintains the motivation and spirit for learning, it balances judgments and potentials of objectives, goals and targets, e.g., tuning of a cognitive load in lifecycle of studies can be balanced by students-teachers; 5) the "scope" addresses to the idea that between two people there is" third dimension as "scope", e.g., a model, artifact, tool, concept, or mental or social thing with which they share and build knowledge, here with a research consortium support.

Then, in viewpoint of the term "problem", it was understood that term "problem-based" includes much more steering by readymade and achieved knowledge, e.g., PERSEUS research and results; someone knows the "problem" and the presented focused knowledge category can be prepared for studies. The "implication" of this study is that the term "scope-elastic-based" is useful for radical development and for totally new type of solutions by learners own creations, and the term "problem-based" is useful for incremental development and for incremental inventions and innovations, however, booth manners needs the support of regional-national innovation systems and funding mechanisms.

In this study, co-creation of competence and learning was realized to using of a body of knowledge in action. The term "shared expertise" was referred to competencies that arise from social interaction, knowledge sharing, confidence, and collective R\&D; and then this setting was included to the shared competence of communities and organized groups of experts and professionals. In learning space of this study, cognition and intelligent activity were not limited to an individual's mental processes, but also rely expanded on socio-culturally developed cognitive real-world realizations. These realizations included physical and conceptual service-artifacts and progress of functionalities. Progressed networked expertise comprised critical, realist, rational and pragmatic views by its nature. The studies were constituted in interactions between individuals, communities and larger networks; and supported by cognitive things and service-artifacts. The learning space was co-evolved by continuously transforming itself in innovative knowledge communities, e.g., sustain integration of research consortiums, higher education institution functions and regional configuration with governance.

For future research: the study revealed that learning by R\&D would be progressed by theoretical core of the metaphors of learning, the implications for amendments followed: 1) the information gathering as pull knowledge; 2) the participation as share knowledge; 3 ) the knowledge creation and co-creation as build knowledge; 4) the knowledge transformation as align and improve knowledge; 5) the knowledge focusing as knowledge push; and 6) the implicit and embedded knowledge, e.g., the self or behaviour of human, ethical sustainability, or unknown causes of kernels of information systems or artificial intelligence. The second phenomenon to future research is that different regions in different countries have needs to share information, international service systems and learning spaces and knowledge flows for their thematic interests and scopes of development, and international research consortiums. This research question would be: how can research consortium related knowledge be designed, improved, realized and shared, e.g., how can Horizon 2020 be understood and described as knowledge steering forum and shared learning space to the global expertise network and European higher education institutions.

\section{Conclusion}

The study comprised knowledge paths and sources as followed: 1) knowledge dissemination, transition and sharing; 2) knowledge transformation; 3) inquired knowledge; 4) focused knowledge or led knowledge; 5) knowledge co-creation and knowledge building; and 6) artifact and service related embedded-implicit knowledge. In this study, the tacit dimension of knowledge was recognized, however, yet the term "tacit" is difficult to the assessment processes in mechanisms of higher education institutions, rather, the described knowledge paths and source were related to the focus of learning by expertise, distributed cognition and shared expertise, collaborative and cultural learning, and R\&D related learning processes, such as which were facilitated in the learning by $R \& D$ studies and thematic curriculum. If this route of $R \& D$ related learning will be extended and generalized, undoubtedly, higher education institutions face new challenges and opportunities due to networked 
expertise and knowledge economy as (Clark, 2007) anticipated.

The realization of described knowledge paths and sources advanced followed: 1) action primarily bridges competencies in the first place and was a way of using knowledge, knowledge paths and sources in real-world achievements and impacts; 2) recognizing of achieved knowledge, knowledge paths and sources were useful in data collection, analysis and triangulation in real-word R\&D cases, research consortiums, and externally funded $R \& D$, especially for realization and design of studies as thematic curriculum and for regional configuration alignments and its integration strategy; 3 ) study exposed that meaning of focused knowledge and global competition is increasing for the recruitment of students and professionals between higher education institutions and regional-global scales of knowledge economy-democracy; 4) higher education institutions have increasing different emphases and focus areas, then different sources and paths of knowledge are useful to future co-planning and co-designing; and 5) international research consortiums can be as steering forums for higher education and knowledge sharing through this challenging and integrative way.

According to this study, the described paths and sources of knowledge were especially significant followed: for development of artifacts and services; for progress of human activity systems, democracy and emancipation of learning; for enablement of new technologies; for designing, testing and improving solutions, methods, models, classifications, techniques and functionalities; for advancement to leadership and management functions and ways of collaboration-steering; for progress of security, safety and risk management; for development of algorithms, data structures and databases; and finally for progress of new academic perspectives of learning.

In overall, the study is in line with Burton Clark: The higher education institutions can increase their contribution to the innovation system; higher education institutions can keep co-creation and innovation processes alive at the regional, national and global levels; and higher education institutions can act as incubators of entrepreneurial skills and value makers for new competences, however, the realization of these targets needs improvements of competence and especially confidence and this affects the change of action in such a demanding way.

\section{Acknowledgements}

This study and the R\&D projects as cases included were funded by The Finnish Funding Agency for Technology and Innovation (TEKES) and European Union's Research and Innovation funding programme FP7.

\section{References}

Argyris, C., \& Schön, D. A. (1996). Organizational Learning II: Theory, Method and Practice. Boston, MA: AddisonWesley.

Asheim, B. (2012). The Changing Role of Learning Regions in the Globalising Knowledge Economy. Regional Studies, 46, 993-1004. http://dx.doi.org/10.1080/00343404.2011.607805

Barrows, H. S., \& Tamblyn, R. M. (1980). Problem-Based Learning (PBL): An Approach to Medical Education. New York: Springer Publishing.

Benbasat, I., Goldstein, D. K., \& Mead, M. (1987). The Case Research Strategy in Studies of Information Systems. MIS Quarterly, 11, 369-386. http://dx.doi.org/10.2307/248684

Bereiter, C. (2007). Learning to Work Creatively with Knowledge. In E. Corte, L. Verschaffel, N. Entwistle, \& J. van Merriënboer (Eds.), Powerful Learning Environments, Unravelling Basic Components and Dimensions (pp. 55-68). Bingley: Emerald Publishing.'

Best, M. (1990). The New Competition: Institutions and Industrial Restructuring. Cambridge, UK: Polity Press.

Bredo, E. (1994). Reconstructing Educational Psychology: Situated Cognition and Deweyian Pragmatism. Educational Psychologist, 29, 23-35.

Brown, J. S., Collins, A., \& Duguid, P. (1989). Situated Cognition and the Culture of Learning. Educational Research, 18, 32-42. http://dx.doi.org/10.3102/0013189X018001032

Burr, V. (1995). An Introduction to Social Constructionism. London: Routledge. http://dx.doi.org/10.4324/9780203299968

Campbell, D. T., \& Fiske, D. W. (1959). Convergent and Discriminant Validation by the Multitrait-Multimethod Matrix. Psychological Bulletin, 56, 81-105. http://dx.doi.org/10.1037/h0046016

Clark, B. (2007). Creating Entrepreneurial Universities: Organizational Pathways of Transformation. Bingley: Emerald Group Publishing Limited.

Cooke, P., \& Morgan, K. (1998). The Associational Economy Firms, Regions, and Innovation. Oxford: Oxford University Press. http://dx.doi.org/10.1093/acprof:oso/9780198290186.001.0001 
Corbin, J., \& Strauss, A. (2008). Basics of Qualitative Research: Techniques and Procedures for Developing Grounded Theory (3rd ed.). Los Angeles, CA: Sage Publications.

Dewey, J. (1897). My Pedagogic Creed. In L. A. Hickman, \& T. M. Alexander (Eds.), The Essential Dewey: Pragmatism, Education, Democracy (pp. 229-235). Bloomington, IN: Indiana University Press.

Dewey, J. (1916). Democracy and Education: An Introduction to the Philosophy of Education. New York: Macmillan.

Dewey, J. (1938). Logic: The Theory of Inquiry. New York: Henry Holt and Company.

Drucker, P. (1969). The Age of Discontinuity: Guidelines to Our Changing Society. New York: Harper and Row.

Dubé, L., \& Paré, G. (2003). Rigor in Information Systems Positivist Case Research: Current Practices, Trends, and Recommendations. MIS Quarterly, 27, 597-635.

Eisenhardt, K. M. (1989). Building Theories from Case Study Research. Academy of Management Review, 14, 532-550.

Engeström, Y. (1987). Learning by Expanding: An Activity-Theoretical Approach to Developmental Research. Helsinki: Orienta-Konsultit Ltd.

Eraut, M. (1994). Developing Professional Knowledge and Competence. London: Flamer Press.

Etzkowitz, H., \& Leydesdorff, L. (1998). The Endless Transition: A “Triple Helix” of University-Industry-Government Relations. Minerva, 36, 203-208.

George, A. L., \& Bennett, A. (2005). Case Studies and Theory Development in the Social Sciences. Cambridge, MA: MIT Press.

Gerring, J. (2007). Case Study Research Principles and Practice. Cambridge: Cambridge University Press.

Gibbons, M., Limoges, C., Nowotny, H., Schwartzman, S., Scott, P., \& Trow, M. (2008). The New Production of Knowledge (12th ed.). Los Angeles, CA: Sage Publications.

Harmaakorpi, V. (2004). Building a Competitive Regional Innovation Environment. Doctoral Dissertation, Espoo: Helsinki University of Technology Lahti Centre.

Herr, K., \& Anderson, G. L. (2005). The Action Research Dissertation: A Guide for Students and Faculty. Thousand Oaks, CA: Sage Publications.

Johansson, J., \& Ylinenpää, H. (2012). Can Regional Innovation Systems Be “Constructed”? In A. Rickne, S. Laestadius, \& H. Etzkowitz (Eds.), Innovation Governance in an Open Economy: Shaping Regional Nodes in a Globalized World (pp. 208-230). London: Routledge.

Kolb, D. (1984). The Process of Experimental Learning. Experiential Learning Experience as the Source of Learning and Development (pp. 19-38). Upper Saddle River, NJ: Prentice-Hall.

Lave, J. (1988). Cognition in Practice. Cambridge: Cambridge University Press. http://dx.doi.org/10.1017/CBO9780511609268

Lewin, K. (1942). Field Theory and Learning in Social Sciences. In D. Cartwright (Ed.), Field Theory in Social Science, Selected Theoretical Papers (pp. 212-230). Washington DC: American Psychological Association!.

Lewin, K. (1946). Action Research and Minority Problems. In G. W. Lewin (Ed.), Resolving Social Conflicts, Selected Papers on Group Dynamic (pp. 143-152). Washington DC: American Psychological Association.

Malecki, E. (2012). Regional Societal Capital: Why It Matters. Regional Studies, 46, 1023-1039. http://dx.doi.org/10.1080/00343404.2011.607806

Mezirow, J. (1981). Critical Theory of Adult Learning and Education. Adult Education, 32, 3-24. http://dx.doi.org/10.1177/074171368103200101

Miles, M. B., \& Huberman, A. M. (1994). Qualitative Data Analysis: An Expanded Sourcebook. Thousand Oaks, CA: Sage Publications.

Nelson, R. R., \& Winter, S. G. (1982). An Evolutionary Theory of Economic Change. Cambridge, MA: Harvard University Press.

Nonaka, I. A., \& Takeuchi, H. A. (1995). The Knowledge-Creating Company: How Japanese Companies Create Dynamic of Innovation. Oxford: Oxford University Press.

Patton, M. (1990). Qualitative Evaluation and Research Methods (2nd ed.). London: Sage Publications.

Peirce, C. S. (1878). How to Make Our Ideas Clear. In H. S. Thayer (Ed.), Pragmatism: The Classic Writings (1982 ed., pp. 79-100). Indianapolis, IN: Hackett Publishing.

Piore, M., \& Sabel, C. H. (1984). The Second Industrial Divide: Possibilities for Prosperity. New York: Basic Books.

Pirinen, R. (2008). Integrative Learning Environments in Perspective of Regional Development. In Proceedings of the Pascal International Conference (Vol. 1, pp. 1-10). Limerick: University of Limerick. 
Pirinen, R. (2009). Thematic Curriculum. International Conference on Education and Educational Technology (pp. 61-66). Genova: WSEAS Press.

Pirinen, R. (2011). Externally Funded Research and Development Projects in Perspective of Learning. International Journal of Engineering Pedagogy, 3, 27-36.

Pirinen, R. (2013). Towards Realization of Research and Development in a University of Applied Sciences. Doctoral Dissertation, Dissertations in Forestry and Natural Sciences, Joensuu: University of Eastern Finland

Pirinen, R. (2014). Learning by Research and Development. Proceedings of the World Engineering Education Forum (WEEF-2014) (pp. 37-46). Dubai: IEEE Press.

Pirinen, R., \& Rajamäki, J. (Eds.) (2010). Integrative Student-Centered Research and Development Work: Rescuing of Intelligence and Electronic Security Core Applications (RIESCA): Sample of Evidence Series. Vantaa: Laurea Publications.

Pirinen, R., Sivlén, E., \& Mantere, E. (2014). Samples of Externally Funded Research and Development Projects in Higher Education: Case Integration Readiness Levels. In Proceedings of the World Engineering Education Forum (WEEF-2014) (pp. 691-700). Dubai: IEEE Press.

Porter, M. E. (1990). The Competitive Advantage of Nations. Harvard Business Review, March-April, 73-93.

Rajamäki, J., Pirinen, R., \& Knuuttila, J. (Eds.) (2012). SATERISK Risks of Satellite-Based Tracking: Sample of Evidence Series. Vantaa: Laurea publications.

Revans, R. (1982). The Origins and Growth of Action Learning. Bromley: Chartwell-Brat.

Rickne, A., Laestadius, S., \& Etzkowitz, H. (Eds.) (2012). Innovation Governance in an Open Economy: Shaping Regional Nodes in a Globalized World. London: Routledge.

Robson, C. (2002). Real World Research (2nd ed.). Oxford: Blackwell Publishing.

Rutten, R., \& Boekema, F. (2012). From Learning Region to Learning in a Socio-Spatial Context. Regional Studies, 46, 981992. http://dx.doi.org/10.1080/00343404.2012.712679

Sawyer, K. (2008). Group Genius: The Creative Power of Collaboration. Cambridge: Perseus Books Group.

Scardamalia, M., \& Bereiter, C. (2006). Knowledge Building: Theory, Pedagogy, and Technology. In K. Sawyer (Ed.), Cambridge Handbook of the Learning Sciences (pp. 97-118). Cambridge: Cambridge University Press.

Schaefer, R. (1967). The School as a Center of Inquiry. New York: Harper and Row Publishing.

Sfard, A. (1998). On Two Metaphors of Learning and the Dangerous of Choosing Just One. Educational Researcher, 27, 413. http://dx.doi.org/10.3102/0013189X027002004

Simon, H. (1996). The Sciences of the Artificial. Cambridge, MA: MIT Press.

Ståhlbröst, A. (2008). Forming Future IT: The Living Lab Way of User Involvement. Doctoral Dissertation, Luleå:' Luleå University of Technology."

Stake, R. (1995). The Art of Case Study Research. Thousand Oaks, CA: Sage Publications.

Storper, M. (1997). The Regional World: Territorial Development in a Global Economy. London and New York: Guilford Press.

Teräs, J. (2008). Regional Science-Based Clusters: A Case Study of Three European Concentrations. Doctoral Dissertation, Oulu: University Press.

Tikanmäki, I., Rajamäki, J., \& Pirinen, R. (Eds.) (2014). Mobile Object Bus Interaction Designing Future Emergency Vehicles: Sample of Evidence Series. Vantaa: Laurea Publications.

Tuomi, I. (1999). Corporate Knowledge: Theory and Practice of Intelligent Organizations. Helsinki: Metaxis.

Vygotsky, L. S. (1978). Interaction between Learning and Development. In M. Cole, V. John-Steiner, S. Scribner, \& E. Souberman (Eds.), L.S. Vygotsky Mind in Society (pp. 79-91). Cambridge, MA: Harvard University Press.

West, R. E. (2009). Communities of Innovation: Exploring Collaborative Creativity within a Community of Graduate Instructional Designers. Doctoral Dissertation, Athens, GA: University of Georgia.

Yin, R. K. (2009). Case Study Research Design and Methods (4th ed.). Thousand Oaks, CA: Sage Publications. 